\title{
Hierarchically nanostructured hydroxyapatite: hydrothermal synthesis, morphology control, growth mechanism, and biological activity
}

This article was published in the following Dove Press journal:

International Journal of Nanomedicine

31 March 2012

Number of times this article has been viewed

\section{Ming-Guo Ma}

Institute of Biomass Chemistry and Technology, College of Materials Science and Technology, Beijing Forestry University, Beijing, People's Republic of China
Correspondence: Ming-Guo Ma Institute of Biomass Chemistry and Technology, College of Materials Science and Technology, Beijing Forestry University, Beijing 100083,

People's Republic of China

Tel +861062336592

Fax +86 I0 62336972

Emailmg_ma@bjfu.edu.cn
Abstract: Hierarchically nanosized hydroxyapatite (HA) with flower-like structure assembled from nanosheets consisting of nanorod building blocks was successfully synthesized by using $\mathrm{CaCl}_{2}, \mathrm{NaH}_{2} \mathrm{PO}_{4}$, and potassium sodium tartrate via a hydrothermal method at $200^{\circ} \mathrm{C}$ for 24 hours. The effects of heating time and heating temperature on the products were investigated. As a chelating ligand and template molecule, the potassium sodium tartrate plays a key role in the formation of hierarchically nanostructured HA. On the basis of experimental results, a possible mechanism based on soft-template and self-assembly was proposed for the formation and growth of the hierarchically nanostructured HA. Cytotoxicity experiments indicated that the hierarchically nanostructured HA had good biocompatibility. It was shown by in-vitro experiments that mesenchymal stem cells could attach to the hierarchically nanostructured HA after being cultured for 48 hours.

Objective: The purpose of this study was to develop facile and effective methods for the synthesis of novel hydroxyapatite (HA) with hierarchical nanostructures assembled from independent and discrete nanobuilding blocks.

Methods: A simple hydrothermal approach was applied to synthesize $\mathrm{HA}$ by using $\mathrm{CaCl}_{2}$, $\mathrm{NaH}_{2} \mathrm{PO}_{4}$, and potassium sodium tartrate at $200^{\circ} \mathrm{C}$ for 24 hours. The cell cytotoxicity of the hierarchically nanostructured HA was tested by MTT (3-(4,5-dimethylthiazol-2-yl)-2,5diphenyltetrazolium bromide) assay.

Results: HA displayed the flower-like structure assembled from nanosheets consisting of nanorod building blocks. The potassium sodium tartrate was used as a chelating ligand, inducing the formation and self-assembly of HA nanorods. The heating time and heating temperature influenced the aggregation and morphology of HA. The cell viability did not decrease with the increasing concentration of hierarchically nanostructured HA added.

Conclusion: A novel, simple and reliable hydrothermal route had been developed for the synthesis of hierarchically nanosized HA with flower-like structure assembled from nanosheets consisting of nanorod building blocks. The HA with the hierarchical nanostructure was formed via a soft-template assisted self-assembly mechanism. The hierarchically nanostructured HA has a good biocompatibility and essentially no in-vitro cytotoxicity.

Keywords: hierarchical, biocompatibility, nanorods, nanosheets

\section{Introduction}

Hierarchical nanostructures have attracted a great deal of attention due to their novel optical, magnetic, and catalytic properties, and they have potential applications as important components and interconnects in nanodevices. ${ }^{1-5}$ It is well known that both the "bottom-up" and "top-down" strategies are two effective approaches for fabricating nanodevices. ${ }^{6-8}$ The self-assembly of building blocks such as nanoparticles, nanorods, 
nanobelts, and complex nanocrystals with well defined morphology, structure, size, and size distribution is considered a "bottom-up" approach. ${ }^{9-11}$ To date, a variety of hierarchical nanostructures of noble metals, ${ }^{12}$ metal sulfides, ${ }^{13,14}$ metal oxides, ${ }^{15-18}$ metal hydroxides, ${ }^{19}$ metal carbonates,,${ }^{20}$ and metal silicates ${ }^{21}$ have been synthesized via self-assembly.

Hydroxyapatite [HA, $\left.\mathrm{Ca}_{10}\left(\mathrm{PO}_{4}\right)_{6}(\mathrm{OH})_{2}\right]$ is a typical biomineral that is abundant in organisms. It can be used as bone scaffolds ${ }^{22}$ and luminescence materials, ${ }^{23}$ and it also has many important applications in drug delivery, ${ }^{24,25}$ and biomedical engineering, ${ }^{26}$ based on its chemical and biological similarity with the mineral constituents of human bones and teeth. ${ }^{27-29}$ To date, various derivatives of HA, such as carbonated HA, ${ }^{30-32}$ strontium HA, ${ }^{33,34}$ F-substituted $\mathrm{HA},{ }^{35,36}$ and HA-based nanocomposites, ${ }^{37,38}$ have been reported. Some successful methods including emulsion, ${ }^{39,40}$ hydrothermal method, ${ }^{41,42}$ solvothermal method, ${ }^{43}$ sonochemical precipitation, ${ }^{44}$ hard-template method, ${ }^{45}$ sol-gel method, ${ }^{46}$ biomimetic method, ${ }^{47,48}$ and microwave irradiation $^{49}$ have been employed in the synthesis of HA. Gajjeraman et $\mathrm{al}^{50}$ used organic constituents of bones and teeth to control the nucleation and assembly of hierarchical HA. Wang et $\mathrm{al}^{51}$ reported the fabrication of HA nanorods by tuning the interfaces between surfactants and the central atoms of HA based on the liquid-solid-solution mechanism. Ortega et $\mathrm{al}^{52}$ used functionalized silica as a template for the nucleation and growth of HA coatings under mild conditions, with an aging period of 6 hours. Wang et a ${ }^{53}$ employed poly(styrene sulfonate) as a modifier in the synthesis of HA microspheres, with controlled size and hierarchical structure by hydrothermal method. Ryu et $\mathrm{al}^{54}$ reported the synthesis of polydopamine-assisted HA inspired by the adhesion mechanism of mussels via a biomineralizing route. Nassif et $\mathrm{al}^{55}$ presented the synthesis of HA nanocrystals via $\mathrm{NH}_{3}$ vapor diffusion into a $\mathrm{CaCl}_{2}-\mathrm{NaH}_{2} \mathrm{PO}_{4}$ mixed solution and B- or A-type carbonate-apatite phases by the addition of $\mathrm{NaHCO}_{3}$ or $\left(\mathrm{NH}_{4}\right)_{2} \mathrm{CO}_{3}$. In a previous paper, the authors reported the preparation of hierarchically nanostructured HA hollow spheres assembled from nanorods by using $\mathrm{CaCl}_{2}, \mathrm{NaH}_{2} \mathrm{PO}_{4}$, and potassium sodium tartrate via a solvothermal method at $200^{\circ} \mathrm{C}$ for 24 hours in a mixture solvent of water/ $N, N$-dimethylformamide. ${ }^{43}$ Most natural biomaterials have complex hierarchical microstructures. ${ }^{56}$ Therefore, the research of hierarchically nanostructured HA is important to the understanding of the biomineralization mechanism and the realization of controllable synthesis of other hierarchical nanostructures.
Reported herein is a simple hydrothermal approach to the synthesis of hierarchically nanostructured HA with flowerlike morphology consisting of nanosheets, which are assembled from nanorod building blocks. The potassium sodium tartrate was used as a chelating ligand and template molecule to induce the synthesis of hierarchically nanostructured HA. The formation mechanism of hierarchically nanostructured HA is proposed based on the experimental details. Cytotoxicity experiments of the hierarchically nanostructured HA have been also carried out. The synthetic method presented here is simple, low-cost, and environmentally friendly (ie, does not use any organic solvents or organic structure-directing surfactants. Furthermore, the final products in this work enrich the hierarchically nanostructured HA architecture family.

\section{Materials and methods}

All chemicals were of analytical grade and used as received without further purification. All experiments were conducted under ambient atmosphere. In a typical experiment, $0.001 \mathrm{~mol}$ of $\mathrm{CaCl}_{2}$ and $0.001 \mathrm{~mol}$ of $\mathrm{C}_{4} \mathrm{H}_{4} \mathrm{O}_{6} \mathrm{KNa} \cdot 4 \mathrm{H}_{2} \mathrm{O}$ (potassium sodium tartrate) were added into $15 \mathrm{~mL}$ of water under vigorous stirring for 30 minutes. Then, $0.0006 \mathrm{~mol}$ of $\mathrm{NaH}_{2} \mathrm{PO}_{4}$ was added into the above solution under vigorous stirring for another 30 minutes. The obtained solution was hydrothermally treated at a fixed temperature $\left(200^{\circ} \mathrm{C}\right)$ for 24 hours without stirring and shaking, and then was allowed to cool to room temperature naturally. Subsequently, the precipitates were separated from the solution by centrifugation, washed by ethanol several times, and dried at $60^{\circ} \mathrm{C}$. Finally, a white powder was obtained. This sample was denoted as sample 1.

In order to investigate the formation mechanism of hierarchically nanostructured $\mathrm{HA}$, another sample was synthesized without $\mathrm{C}_{4} \mathrm{H}_{4} \mathrm{O}_{6} \mathrm{KNa} \cdot 4 \mathrm{H}_{2} \mathrm{O}$, keeping the other conditions the same with those in the preparation of sample 1 . This sample was denoted as sample 7. Moreover, another sample was synthesized without $\mathrm{NaH}_{2} \mathrm{PO}_{4}$ at room temperature for 30 minutes, keeping the other conditions the same. This sample was denoted as sample 8. Another sample was also synthesized without $\mathrm{NaH}_{2} \mathrm{PO}_{4}$, keeping the other conditions the same. This sample was denoted as sample 9. The detailed experimental parameters for the synthesis of some typical samples were listed in Table 1.

The $\mathrm{pH}$ values of the reaction solutions in the preparation of sample 1 (with potassium sodium tartrate) and sample 7 (without potassium sodium tartrate) were 4.92 and 3.97 before 
Table I Detailed experimental parameters for the synthesis of some typical samples by hydrothermal method

\begin{tabular}{|c|c|c|c|}
\hline Sample & Temperature & Time & Reaction system \\
\hline I & $200^{\circ} \mathrm{C}$ & 24 hours & 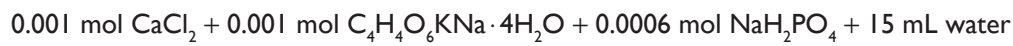 \\
\hline 2 & $200^{\circ} \mathrm{C}$ & 12 hours & 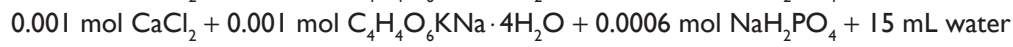 \\
\hline 3 & $200^{\circ} \mathrm{C}$ & 3 hours & 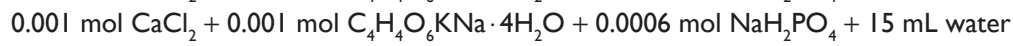 \\
\hline 4 & $200^{\circ} \mathrm{C}$ & 4 hours & $0.001 \mathrm{~mol} \mathrm{CaCl}{ }_{2}+0.00 \mathrm{I} \mathrm{mol} \mathrm{C} \mathrm{H}_{4} \mathrm{O}_{6} \mathrm{KNa} \cdot 4 \mathrm{H}_{2} \mathrm{O}+0.0006 \mathrm{~mol} \mathrm{NaH}_{2} \mathrm{PO}_{4}+\mathrm{I} 5 \mathrm{~mL}$ water \\
\hline 5 & $200^{\circ} \mathrm{C}$ & 6 hours & 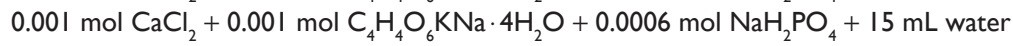 \\
\hline 6 & $160^{\circ} \mathrm{C}$ & 24 hours & $0.001 \mathrm{~mol} \mathrm{CaCl}{ }_{2}+0.001 \mathrm{~mol} \mathrm{C}_{4} \mathrm{H}_{4} \mathrm{O}_{6} \mathrm{KNa} \cdot 4 \mathrm{H}_{2} \mathrm{O}+0.0006 \mathrm{~mol} \mathrm{NaH} \mathrm{PO}_{4}+\mathrm{I} 5 \mathrm{~mL}$ water \\
\hline 7 & $200^{\circ} \mathrm{C}$ & 24 hours & $0.001 \mathrm{~mol} \mathrm{CaCl}{ }_{2}+0.0006 \mathrm{~mol} \mathrm{NaH}_{2} \mathrm{PO}_{4}+15 \mathrm{~mL}$ water \\
\hline 8 & Room temperature & 30 minutes & $0.001 \mathrm{~mol} \mathrm{CaCl}+0.001 \mathrm{~mol} \mathrm{C} \mathrm{H}_{4} \mathrm{O}_{6} \mathrm{KNa} \cdot 4 \mathrm{H}_{2} \mathrm{O}+15 \mathrm{~mL}$ water \\
\hline 9 & $200^{\circ} \mathrm{C}$ & 24 hours & $0.001 \mathrm{~mol} \mathrm{CaCl}+0.001 \mathrm{~mol} \mathrm{C}_{4} \mathrm{H}_{4} \mathrm{O}_{6} \mathrm{KNa} \cdot 4 \mathrm{H}_{2} \mathrm{O}+15 \mathrm{~mL}$ water \\
\hline
\end{tabular}

hydrothermal treatment, respectively. After the reaction solutions had been hydrothermally treated, the $\mathrm{pH}$ values were 3.74 and 2.66 in the preparation of sample 1 and sample 7 , respectively.

$\mathrm{X}$-ray powder diffraction (XRD) patterns were recorded with $2 \theta$ range from $2^{\circ}$ to $70^{\circ}$ on a D/Max 2200-PC diffractometer (Rigaku Corporation, Tokyo, Japan) with $\mathrm{CuK} \alpha$ radiation $(\lambda=0.15418 \mathrm{~nm})$ and graphite monochromator at ambient temperature. Field emission scanning electron microscopy (FE-SEM) images were recorded on a JSM-6700F field-emission scanning electron microscope (JEOL, Tokyo, Japan). SEM images were recorded on a Hitachi $3400 \mathrm{~N}$ scanning electron microscope. All samples were $\mathrm{Au}$ coated prior to the observation by FE-SEM and SEM. Transmission electron microscopy (TEM) imaging, selected area electron diffraction (SAED), high-resolution TEM (HR-TEM) imaging, and energy-dispersive X-ray analysis (EDS) were performed on a JEM-2010 electron microscope (JEOL) with the accelerating voltage of $200 \mathrm{kV}$. A Fourier transform infrared (FTIR) spectroscopy was carried out with a Nexus spectrometer (Thermo Nicolet, Madison, WI), using the $\mathrm{KBr}$ disk method. The $\mathrm{Ca} / \mathrm{P}$ atomic ratio was also obtained by inductively coupled plasma optical emission spectrometry (ICP-OES), using an Optima 5300DV (PerkinElmer Life and Analytical Sciences, Shelton, CT).

The human gastric carcinoma cells (MGC-803), which were cultured in a RPMI-1640 medium supplemented with $10 \%$ fetal bovine serum and $1 \%$ penicillin-streptomycin at $37^{\circ} \mathrm{C}$ for 48 hours, were used for the cell viability test. The cells were seeded in 96-well flat-bottom microassay plates at a concentration of $1 \times 10^{4}$ cells $/ \mathrm{mL}$, and cultured for 24 hours. The sterilized HA samples were added into wells at a concentration from 10 to $100 \mu \mathrm{g} / \mathrm{mL}$, and were co-cultured with cells for 48 hours. The sample free tissue culture plate was used as a control. Cell viability was quantitatively analyzed by
MTT (3-(4,5-dimethylthiazol-2-yl)-2,5-diphenyltetrazolium bromide) assay. Data are representative as the mean value of five parallel experiments.

\section{Results and discussion}

The typical sample (sample 1) was synthesized by using $\mathrm{CaCl}_{2}, \mathrm{NaH}_{2} \mathrm{PO}_{4}$, and potassium sodium tartrate via a hydrothermal method at $200^{\circ} \mathrm{C}$ for 24 hours. The morphology of the sample was investigated with FE-SEM. Figure 1A shows HA with flower-like morphology assembled from nanosheets. Figure 1B shows a unit of typical flower-like morphology. Figure $1 \mathrm{C}$ shows that the nanosheets are assembled from substructured nanorods as the basic unit. Figure 1D displays an individual nanosheet. The nanorods have diameters of $25-50 \mathrm{~nm}$ and lengths of about several micrometers. This is the first report on the synthesis of hierarchically nanostructured HA with flower-like morphology assembled from nanosheets consisting of nanorod units.

The morphology and microstructure of the sample were further investigated by TEM, SAED, and HR-TEM. Figure 2A and $\mathrm{B}$ show TEM images of the hierarchically nanostructured HA, from which one can see the nanosheets with relatively uniform size. Figure $2 \mathrm{C}$ displays the edges of the nanosheets built up by nanorods. An individual nanorod with smooth surface is shown in Figure 2D, the inset of which shows the corresponding SAED pattern, indicating the single crystalline structure of the basic nanorod unit. Figure 2E shows the corresponding HR-TEM image of HA nanorod. The periodic fringe spacing of $3.43 \AA$ corresponds to the $\mathrm{d}$-spacing of (002) plane of the hexagonal HA. As seen in Figure 2F, the surface of the nanorod became rough after exposure to electron beam irradiation. Similar cases of one-dimensional structures changing their morphology under electron beam irradiation have been reported in; for example, $\mathrm{PbCrO}_{4}$ rods, ${ }^{57} \mathrm{Ag}_{6} \mathrm{Mo}_{10} \mathrm{O}_{33}$ rods, ${ }^{58}$ and Bi nanotubes, ${ }^{59}$ etc. 

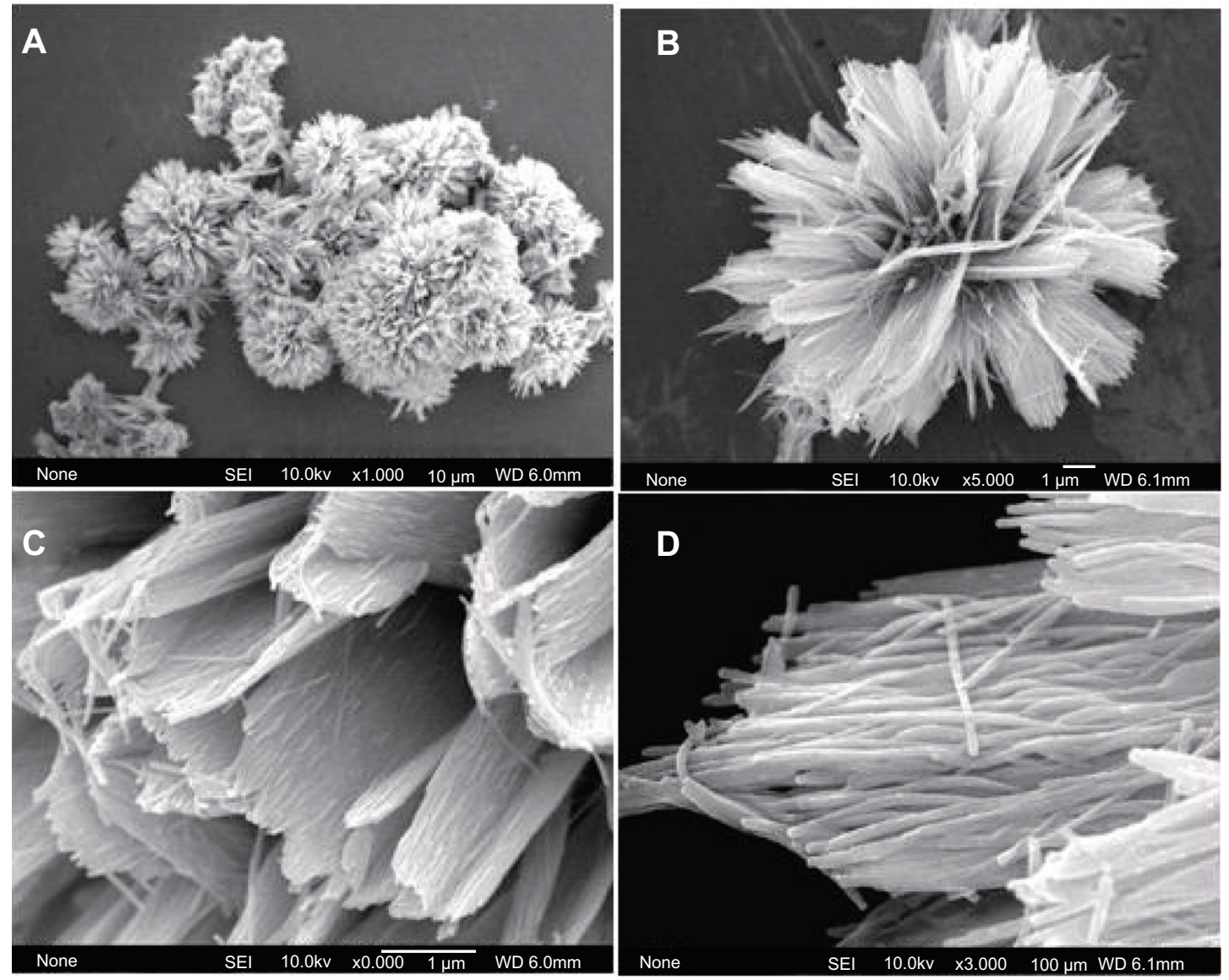

Figure I Field emission scanning electron microscopy images of hierarchically nanostructured hydroxyapatite (sample I).
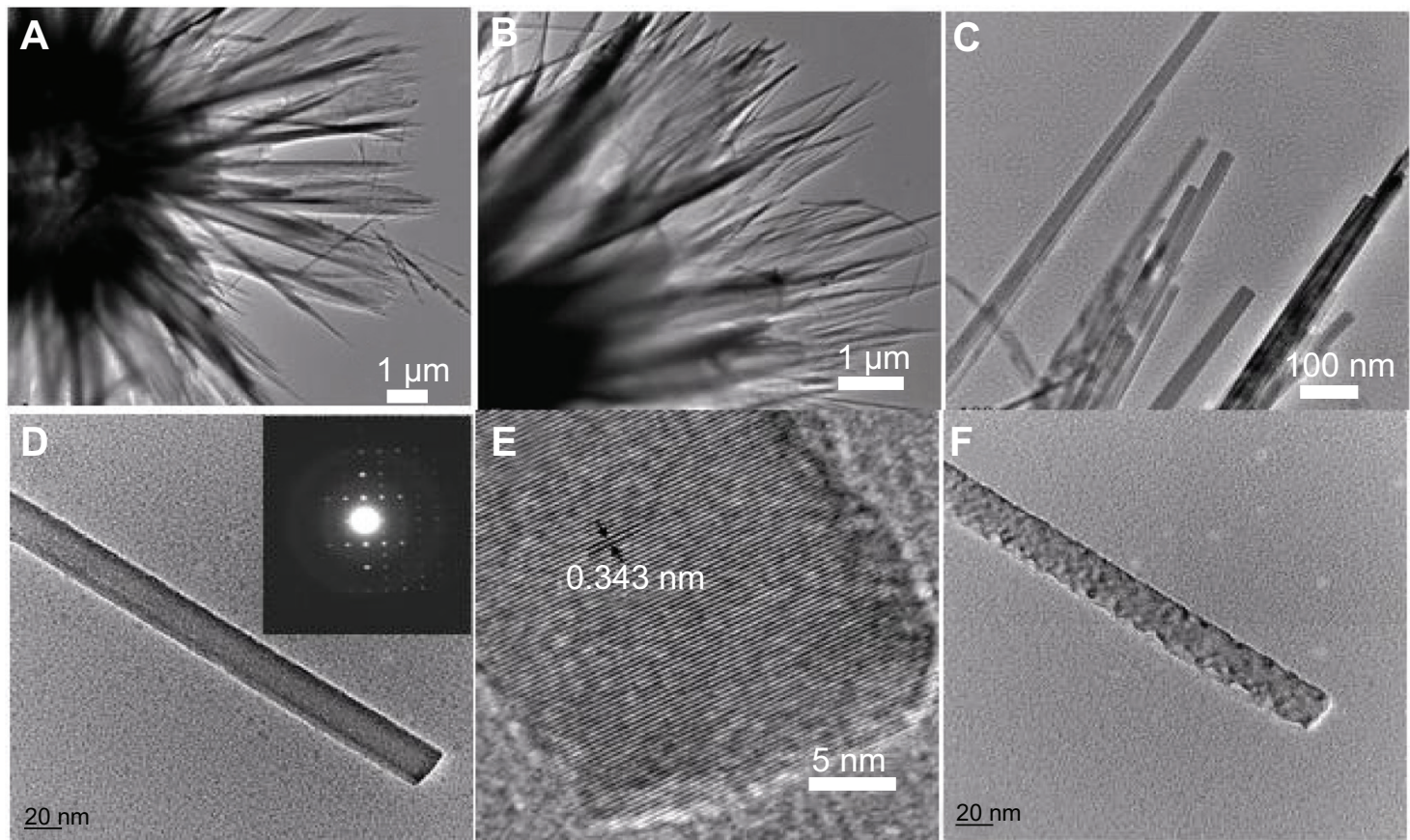

Figure 2 TEM images of hierarchically nanostructured hydroxyapatite (sample I): (A and B) the edges of the flower-like assembly; (C) the edges of the nanosheets; (D) an individual nanorod; (E) the corresponding high-resolution TEM micrograph of (D); and (F) the nanorod after exposure to electron beam irradiation. The inset of (D) shows the corresponding selected area electron diffraction pattern.

Abbreviation: TEM, transmission electron microscopy

E

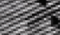

0.3 3 nin

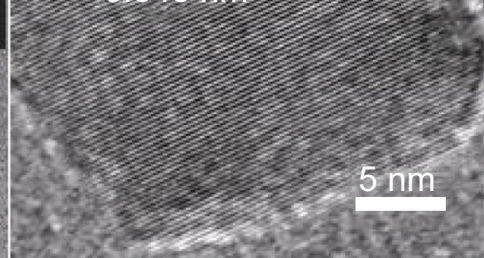


The crystal phase and molecular structure of the typical sample were characterized by XRD and FTIR. Figure 3A shows the XRD pattern of the typical sample, which consisted of a well-crystalline phase with a hexagonal-structured HA (JCPDS 84-1998). No peaks from impurities such as $\mathrm{CaHPO}_{4}$ were observed. The FTIR spectra (shown at (C) and (D) in Figure 3) were used to identify the functional groups of the samples. Figure $3 \mathrm{C}$ shows the FTIR spectrum of the same sample as in (A). A broad strong peak with a center around $3429 \mathrm{~cm}^{-1}$ can be assigned to the adsorbed water on HA. ${ }^{60}$ The characteristic stretching mode of the $-\mathrm{OH}$ vibration on HA was located around $3570 \mathrm{~cm}^{-1},{ }_{1}^{61}$ which is not clearly observed in Figure 3C because of the overlapping with the strong band of the adsorbed water around $3429 \mathrm{~cm}^{-1} .60$ Furthermore, the weak peaks at about 1405 and $1462 \mathrm{~cm}^{-1}$ should be attributed to the absorption bands of $\mathrm{CO}_{3}^{2-}$, indicating the presence of carbonate ions, which came from the atmosphere. ${ }^{62}$ The intense peaks located at 1032, 605, and $565 \mathrm{~cm}^{-1}$ can be attributed to the $\mathrm{PO}_{4}^{3-} \cdot{ }^{33}$ It should be noted that the similar result that the characteristic stretching mode of the $-\mathrm{OH}$ vibration was overlapped with the strong band of the adsorbed water has been observed in a previous study on HA. ${ }^{64}$
The relative intensity of the peak at about $3540 \mathrm{~cm}^{-1}$ decreased after the calcination of the sample at $800^{\circ} \mathrm{C}$ for 3 hours (see (D) in Figure 3), compared with that in (C). The XRD pattern showed the calcination effect on the crystal structure (see (B) in Figure 3); the pattern shows that the sample after calcination at $800^{\circ} \mathrm{C}$ for 3 hours had a similar XRD pattern with that in (A), indicating that the crystal phase of the sample did not change. However, the relative intensity of (112) and (300) planes in (B) in Figure 3 increased compared with those in (A). The crystal units of HA could be rearranged after high temperature calcination, resulting in better crystallized planes such as (112) and (300) planes. On the basis of the XRD and FTIR results, one can confirm that the sample is HA.

EDS is a technique used to identify the elemental composition of the typical product, as shown in Figure 4. The figure shows that the sample consisted of $\mathrm{Ca}, \mathrm{P}$, and $\mathrm{O}$, with a $\mathrm{Ca} / \mathrm{P}$ atomic ratio of 1.62 , in good agreement with the stoichiometric composition of HA, further implying the formation of pure phase $\mathrm{HA}$. The $\mathrm{Cu}$ signal comes from the TEM grid. The $\mathrm{Ca} / \mathrm{P}$ atomic ratio was also tested by ICP-OES. The obtained value of the $\mathrm{Ca} / \mathrm{P}$ atomic ratio was 1.73 , which is close to the result obtained by EDS analysis.
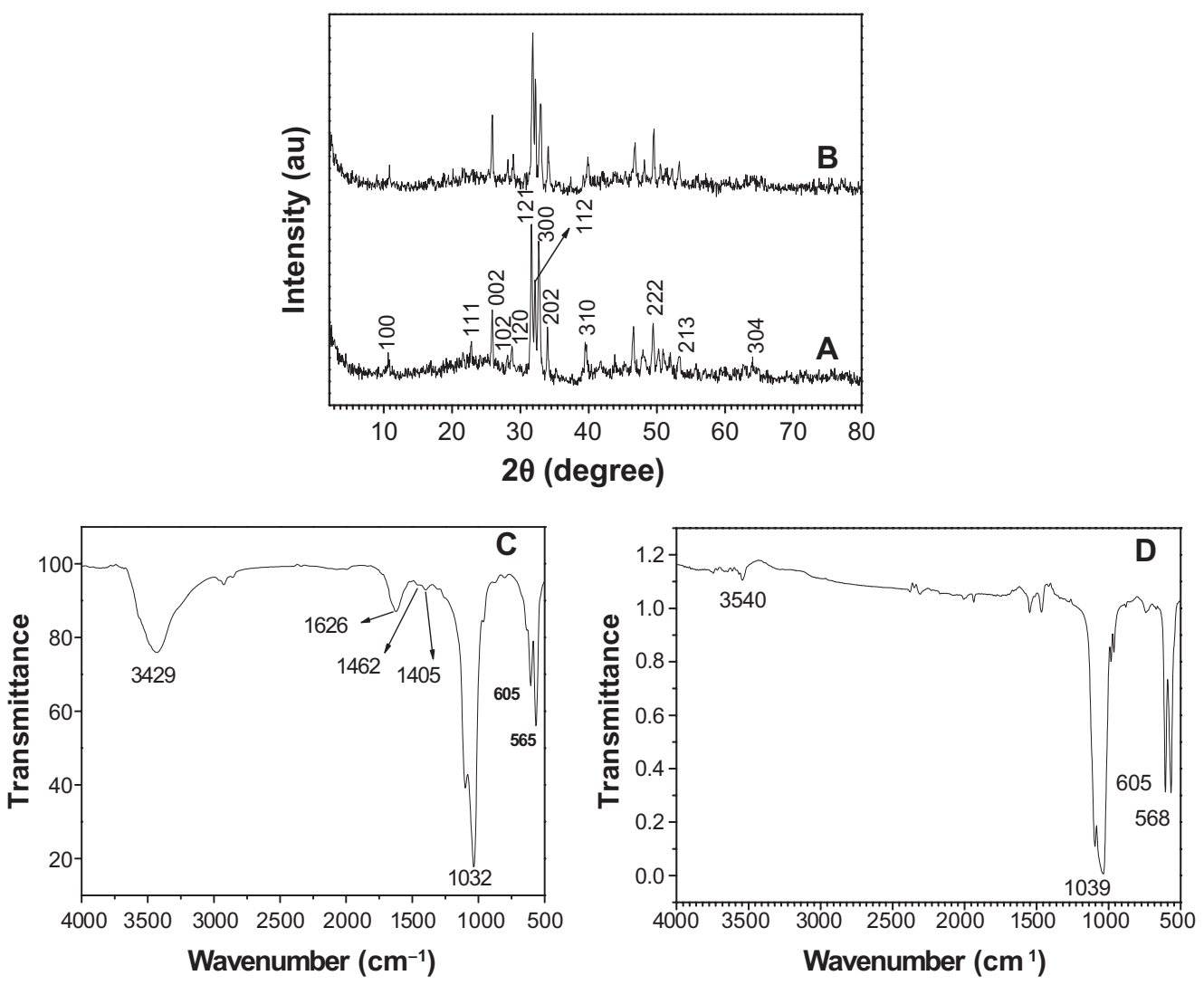

Figure 3 A typical XRD pattern (A) and FTIR spectrum (C) of hydroxyapatite powders prepared by hydrothermal method at $200^{\circ} \mathrm{C}$ for 24 hours; $\mathrm{XRD}$ pattern (B) and FTIR spectrum (D) of the sample prepared by calcination of $(A)$ at $800^{\circ} \mathrm{C}$ for 3 hours.

Abbreviations: FTIR, Fourier transform infrared; XRD, X-ray powder diffraction. 


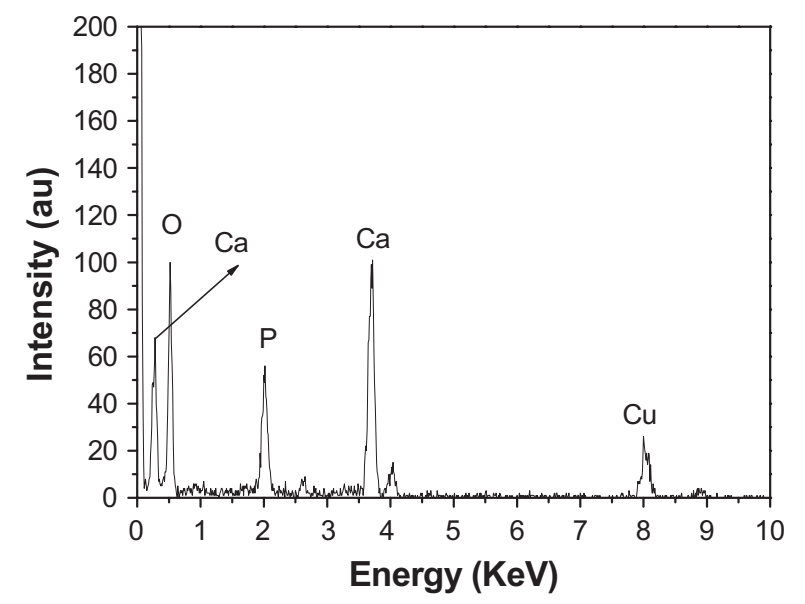

Figure 4 Energy-dispersive $X$-ray analysis spectrum of hierarchically nanostructured hydroxyapatite (sample I).

Investigation has been conducted on the effect of the reaction time on the crystallinity and morphology of HA. All the samples consisted of a single phase of HA (see Figure 5). Moreover, the peak intensity of the samples increased with the increasing heating time, indicating that the crystallinity was gradually improved during the reaction. When the hydrothermal time was 12 hours, hierarchically nanostructured HA was observed (Figure 6). Compared with that shown in Figure 1, the size of the flower-like particles decreased and the nanorods were not clearly observed (Figure 6D). When the reaction time was 3 hours, spherical structures assembled from nanosheets and flower-like structures consisting of nanorods were obtained (Figure 7A). When the heating time was increased to 4 hours, there were no significant

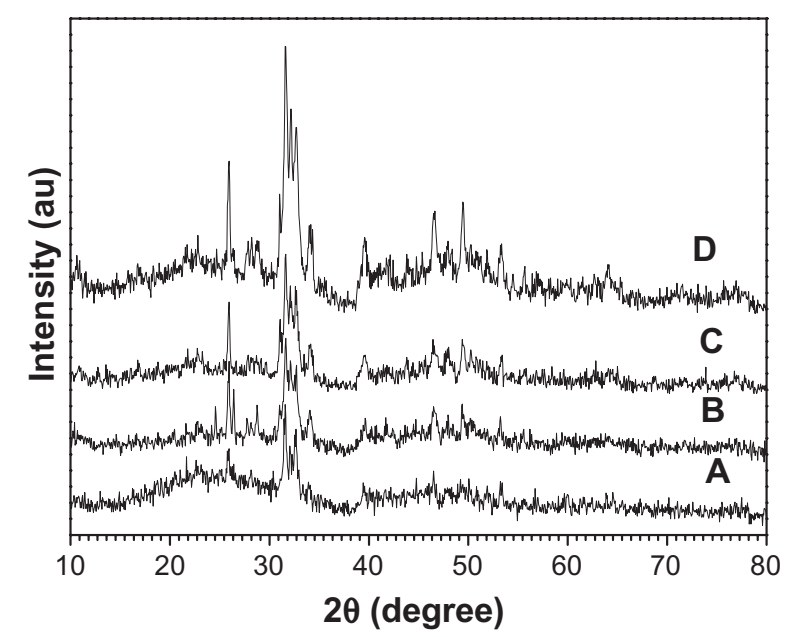

Figure 5 X-ray powder diffraction patterns of hierarchically nanostructured hydroxyapatite prepared by hydrothermal method at $200^{\circ} \mathrm{C}$ for different lengths of time: 3 hours (sample 3) (A); 4 hours (sample 4) (B); 6 hours (sample 5) (C); and 12 hours (sample 2) (D). differences in the morphologies of the samples for 3- and 4-hour hydrothermal treatments (Figure 7B). When the heating time was increased to 6 hours, though some irregular morphologies were also observed, the number of flower-like structures consisting of nanosheets increased (Figure 7C). Figures 1, 6, and 7, clearly show the morphology evolution process of hierarchically nanostructured HA during the hydrothermal process.

The influence of heating temperature on the morphology of prepared HA was also studied. HA sample with a different morphology (Figure 8) was prepared at $160^{\circ} \mathrm{C}$ for 24 hours. The flower-like assemblage of nanorods and spherically assembled nanosheets were observed as the major morphologies, while the big blocks were observed as the minor one (Figure 8A). Figure 8B and $\mathrm{C}$ show the typical flower-like structure assemblage of nanorods and spherically assembled nanosheets, respectively. Figure 8D displayed the detailed structure of a single sphere, from which the saw-like structure was observed at the end of the nanosheets.

On the basis of the above experimental results, softtemplate-assisted self-assembly could be proposed as a formation mechanism of the hierarchically nanostructured HA consisting of nanosheets assembled from nanorods, which is briefly illustrated in Figure 9. At the initial stage, the complex of $\mathrm{Ca}^{2+}$-tartrate was firstly formed by nucleation. Then, HA with similar morphology was obtained by the addition of $\mathrm{NaH}_{2} \mathrm{PO}_{4}$. After that, the individual nanorods aggregated into a sheet-like structure, and the nanosheets aggregated into the hierarchically nanostructured HA by using $\mathrm{Ca}^{2+}$-tartrate as the template. The degree of the assembly and the size of the congeries increased along with the increasing reaction time. Finally, hierarchically nanostructured HA with flower-like morphology assembled from nanosheets consisting of nanorod building blocks was fabricated. It should be noted that the potassium sodium tartrate played a key role in the synthesis of hierarchically nanostructured HA. When the potassium sodium tartrate was not present, the monetite was formed, and the corresponding morphology is shown in Figure 10A-C. The figure shows the big blocks with irregular shapes, and no hierarchically nanostructured HA with flower-like structure consisting of nanosheets was observed. The potassium sodium tartrate was used as a chelating ligand inducing the synthesis and self-assembly of hierarchically nanostructured HA. In the presence of $\mathrm{C}_{4} \mathrm{H}_{4} \mathrm{O}_{6}{ }^{2-}$, the complex of $\mathrm{Ca}^{2+}$-tartrate was formed due to the strong coordination ability of $\mathrm{C}_{4} \mathrm{H}_{4} \mathrm{O}_{6}{ }^{2-} \cdot{ }^{65}$ Figure 10D-F displayed the SEM images of the sample synthesized by using $\mathrm{CaCl}_{2}$ and $\mathrm{C}_{4} \mathrm{H}_{4} \mathrm{O}_{6} \mathrm{KNa} \cdot 4 \mathrm{H}_{2} \mathrm{O}$ at room 

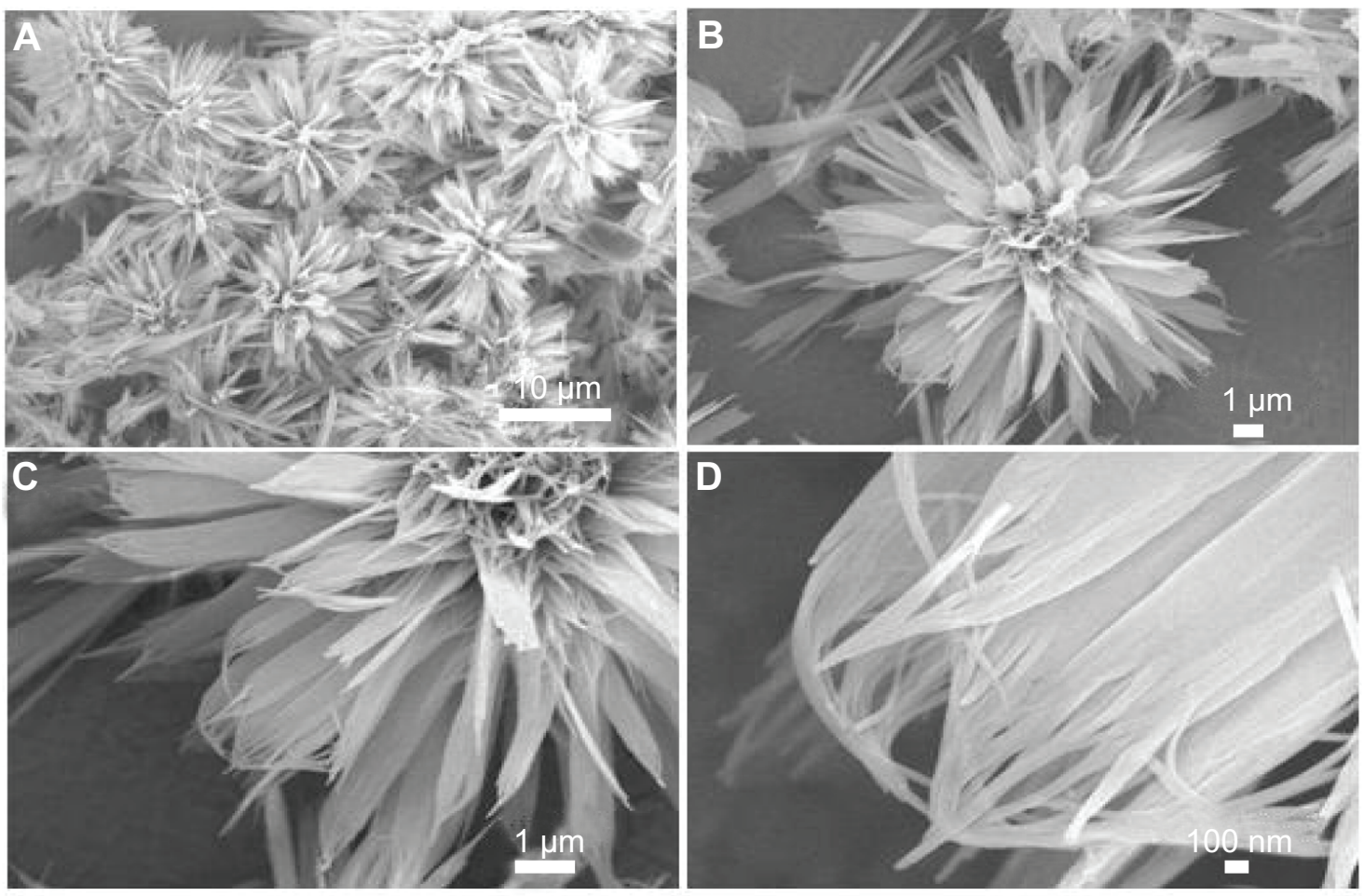

Figure 6 Scanning electron microscopy images of hierarchically nanostructured hydroxyapatite prepared by hydrothermal method at $200^{\circ} \mathrm{C}$ for 12 hours (sample 2 ).

temperature for 30 minutes before hydrothermal treatment. The figures show that flakes and congregated flakes were obtained. Hierarchical spherical nanostructures consisting of nanosheets were observed after hydrothermal treatment, as shown in Figure 10G-I. The complex of $\mathrm{Ca}^{2+}$-tartrate reacted with $\mathrm{NaH}_{2} \mathrm{PO}_{4}$ to form $\mathrm{HA}$, and then hierarchically nanostructured HA with flower-like units assembled from nanosheets consisting of nanorod building blocks was then gradually formed. Therefore, the complex of $\mathrm{Ca}^{2+}$-tartrate was used as a soft-template to induce the evolution of HA with special structure and morphology. Moreover, the $\mathrm{pH}$ values of the reaction solutions in sample 7 (without potassium sodium tartrate) before and after hydrothermal treatment were 3.97 and 2.66, respectively; while the $\mathrm{pH}$ values of the reaction solutions with potassium sodium tartrate before and after hydrothermal treatment were increased to 4.92 and 3.74 , respectively. These results implied that the addition of potassium sodium tartrate increased the $\mathrm{pH}$ value in the system and favored the fabrication of HA, for the most stable phase of HA existed in a basic solution. ${ }^{66}$ In our previous work, with the assistance of potassium sodium tartrate the hierarchically nanostructured HA, hollow spheres were obtained via a solvothermal process at $200^{\circ} \mathrm{C}$ for 24 hours in a mixture solvent of water/ $\mathrm{N}, \mathrm{N}$-dimethylformamide. ${ }^{64}$ The $\mathrm{C}_{4} \mathrm{H}_{4} \mathrm{O}_{6}{ }^{2-}$ has been also used in the preparation of $\mathrm{CuO}$ spheres ${ }^{67}$ and $\mathrm{Cu}_{2} \mathrm{O}$ nanocages.$^{68}$ Moreover, it is well known that the HA nanorods are formed due to the anisotropy of HA. ${ }^{69-71}$ The growth and self-assembly of HA nanorods
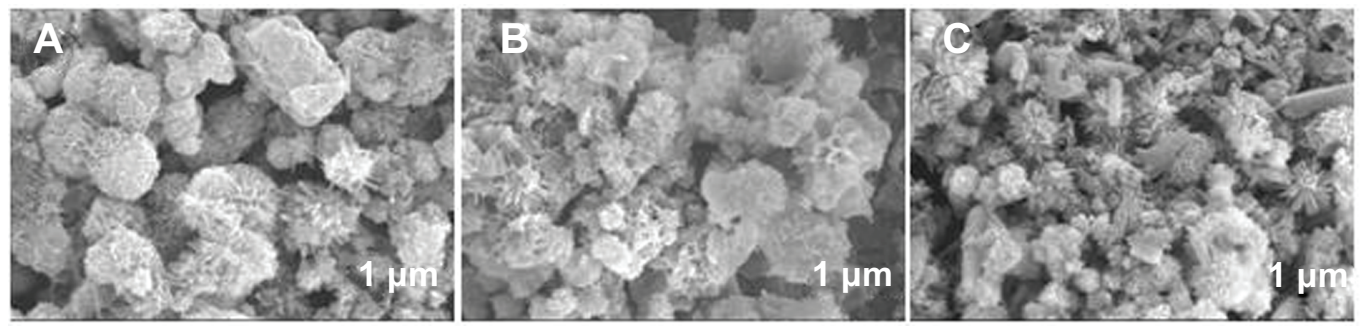

Figure 7 Scanning electron microscopy images of hierarchically nanostructured hydroxyapatite prepared by hydrothermal method at $200^{\circ} \mathrm{C}$ for different lengths of time: (A) 3 hours (sample 3); (B) 4 hours (sample 4); (C) 6 hours (sample 5). 

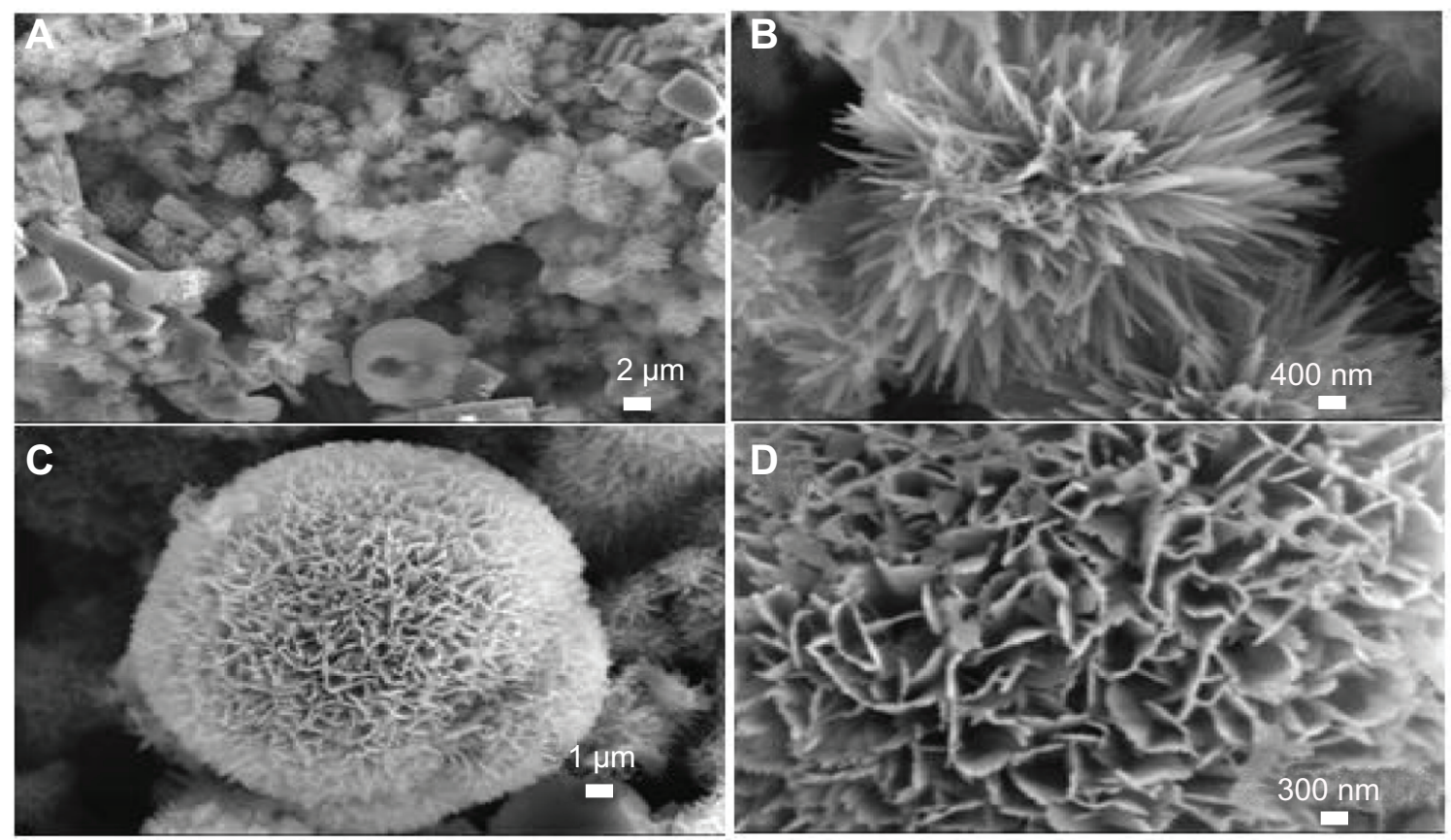

Figure 8 Scanning electron microscopy images of hierarchically nanostructured hydroxyapatite prepared by hydrothermal method at $160^{\circ} \mathrm{C}$ for 24 hours (sample 6 ).

also induced the formation of hierarchically nanostructured HA with increasing reaction time. Finally, the hierarchically nanostructured HA was synthesized. Generally speaking, the morphology evolution of hierarchically nanostructured HA is very complicated. The various reagents and steps including chelating ligand, soft-template, nucleation, growth, and self-assembly were involved in the evolution of hierarchically nanostructured HA, which was also affected by the intrinsic growth habit of HA itself. Of course, the detailed formation mechanism of hierarchically nanostructured HA needs to be further explored.

In the synthesis system, $\mathrm{CaCl}_{2}, \mathrm{NaH}_{2} \mathrm{PO}_{4}$, and potassium sodium tartrate have almost no biological toxicity, and thus are biologically safe. Therefore, it is expected that the hierarchically nanostructured HA is biologically compatible. Mesenchymal stem cells are multipotent stem cells that can differentiate into a variety of cell types and are widely used as seed cells in tissue engineering. The MTT assay was performed as a simple colorimetric assay to measure cell cytotoxicity. In this study, the cytotoxicity of the hierarchically nanostructured HA was tested by comparison with the reference tissue culture plate (Figure 11). When the hierarchically nanostructured HA concentration in the well was $10 \mu \mathrm{g} / \mathrm{mL}$, the corresponding cell viability value was $97.2 \%$. Only a slight reduction $(2.8 \%)$ in cellular viability was observed with the addition of a small

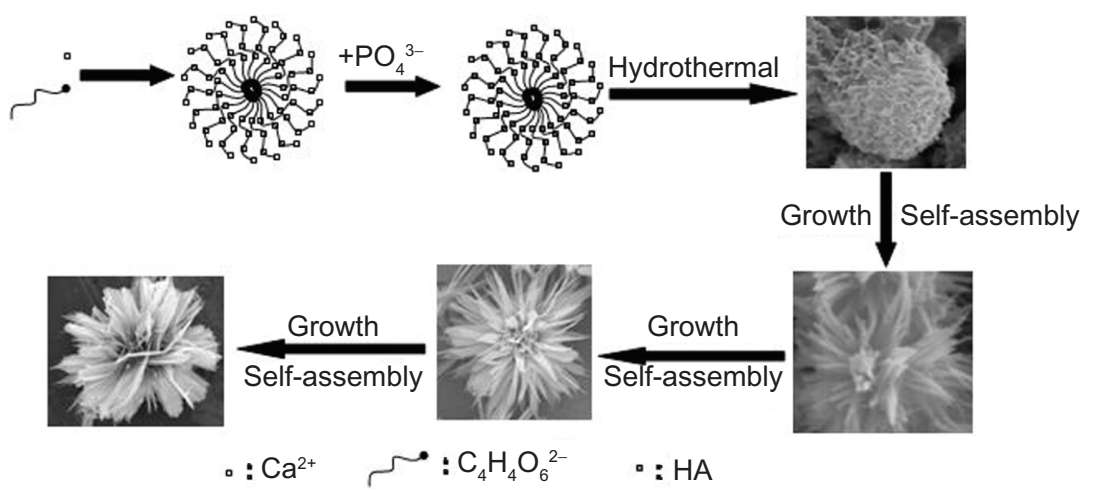

Figure 9 Schematic representation of the formation mechanism of hierarchically nanostructured HA. Abbreviation: HA, hydroxyapatite. 

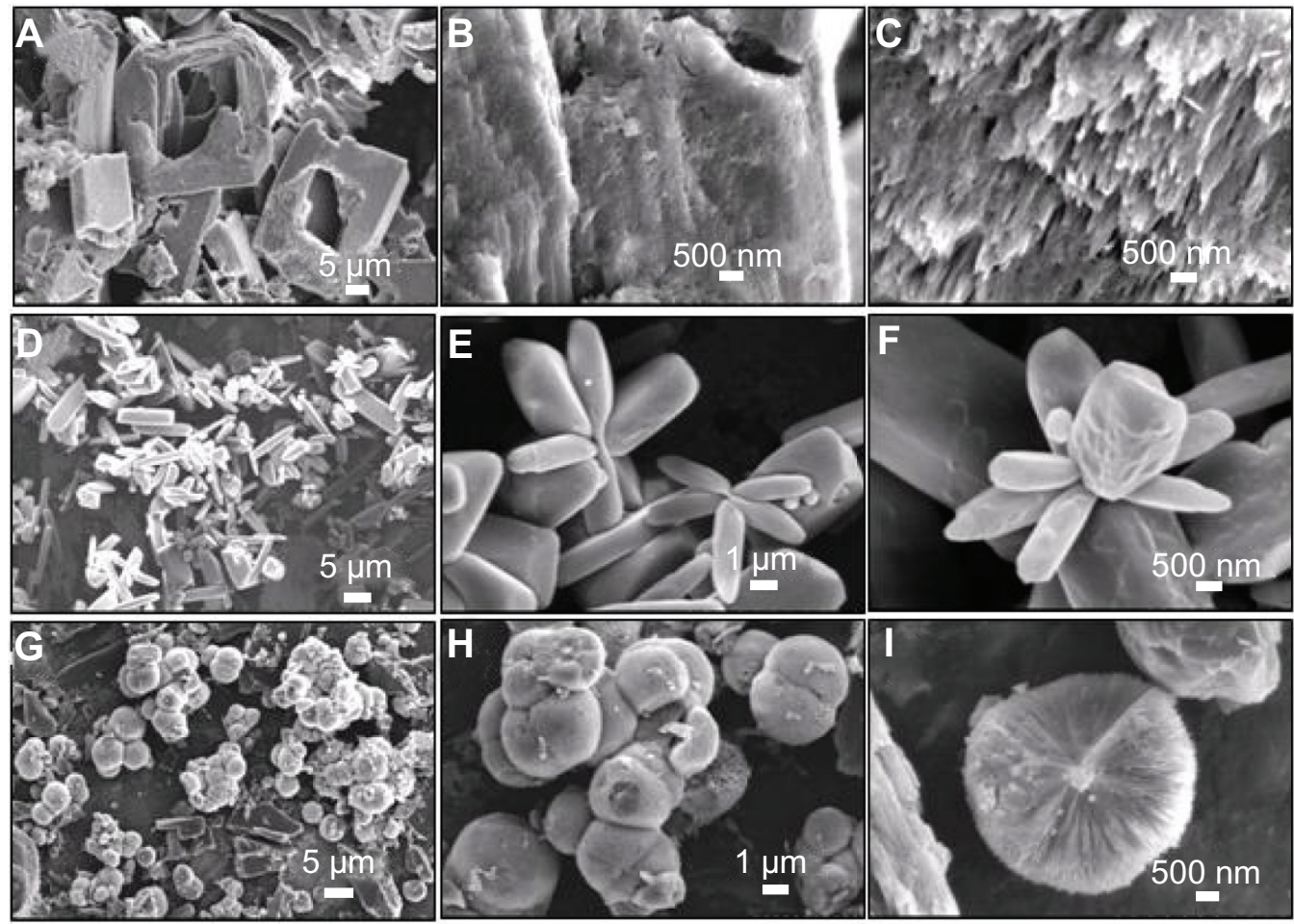

Figure 10 Scanning electron microscopy images of $(\mathbf{A}-\mathbf{C})$ the sample synthesized by using $\mathrm{CaCl}_{2}$ and $\mathrm{NaH}_{2} \mathrm{PO}_{4}$ without the addition of $\mathrm{C}_{4} \mathrm{H}_{4} \mathrm{O}_{6} \mathrm{KNa}_{4} 4 \mathrm{H}_{2} \mathrm{O}$ at $200^{\circ} \mathrm{C}$ for 24 hours (sample 7); (D-F) the sample synthesized by using $\mathrm{CaCl}_{2}$ and $\mathrm{C}_{4} \mathrm{H}_{4} \mathrm{O}_{6} \mathrm{KNa} \cdot 4 \mathrm{H}_{2} \mathrm{O}$ at room temperature for 30 minutes (sample 8); and (G-I) the sample synthesized by using $\mathrm{CaCl}_{2}$ and $\mathrm{C}_{4} \mathrm{H}_{4} \mathrm{O}_{6} \mathrm{KNa} \cdot 4 \mathrm{H}_{2} \mathrm{O}$ at $200^{\circ} \mathrm{C}$ for 24 hours (sample 9).

amount of hierarchically nanostructured HA. It is interesting to note that the cell viability value was still $99.5 \%$, even though the concentration of hierarchically nanostructured HA increased from 10 to $100 \mu \mathrm{g} / \mathrm{mL}$ after incubation for 48 hours. Figure 11 clearly shows that the cell viability did not decrease with the increasing concentration of hierarchically nanostructured HA added. These results indicate that

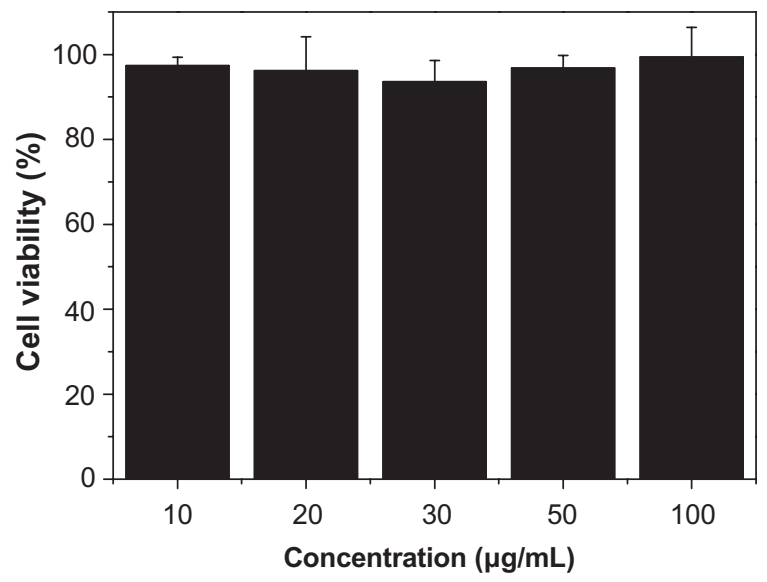

Figure II Viability of normal human fibroblasts incubated with hierarchically nanostructured hydroxyapatite at different concentrations.

Notes: They were determined by counting the survival cells per well in comparison with untreated cells. The error bars denote standard deviations. the hierarchically nanostructured HA has a slight effect on the normal human fibroblast cell viability after 48 hours culture, and little in-vitro cytotoxicity, and can be expected to be used as a biocompatible material.

\section{Conclusion}

In summary, we report a novel, simple, and reliable hydrothermal route for the synthesis of hierarchically nanosized HA with flower-like structure assembled from nanosheets consisting of nanorod building blocks. The potassium sodium tartrate was used as a chelating ligand inducing the formation and self-assembly of HA nanorods. The heating time and heating temperature influenced the aggregation and morphology of HA. Since the HA with the hierarchical nanostructure was formed via a soft-templateassisted self-assembly, prolonged heating time would facilitate the molecular rearrangement and improve the crystallinity of the building blocks such as nanosheets and nanorods. Different reaction temperatures would provide different Gibbs energy in the sealed reaction system, thus leading to different final hierarchical nanostructures. The research of the mechanism of the hierarchical HA does a favor to the synthesis of other nanomaterials with the similar morphology and structure. 
Cytotoxicity experiments indicate that the hierarchically nanostructured HA has good biocompatibility and essentially no in-vitro cytotoxicity.

\section{Acknowledgments}

Financial support from the National Natural Science Foundation of China (31070511), Research Fund for the Doctoral Program of Higher Education of China (20100014120010), China Postdoctoral Science Special Foundation (201003059), and the Program for New Century Excellent Talents in University is gratefully acknowledged.

\section{Disclosure}

The author reports no conflicts of interest in this work.

\section{References}

1. Comini E, Baratto C, Faglia G, Ferroni M, Vomiero A, Sberveglieri G. Quasi-one dimensional metal oxide semiconductors: preparation, characterization and application as chemical sensors. Progr Mater Sci. 2009;54:1-67.

2. Snyder MA, Tsapatsis M. Hierarchical nanomanufacturing: from shaped zeolite nanoparticles to high-performance separation membranes. Angew Chem Int Ed Engl. 2007;46:7560-7573.

3. Xu AW, Ma YR, Colfen H. Biomimetic mineralization. J Mater Chem. 2007; 17:415-449.

4. Sanchez C, Arribart H, Guille MMG. Biomimetism and bioinspiration as tools for the design of innovative materials and systems. Nat Mater. 2005;4:277-288.

5. Soler-Illia GJ, Sanchez C, Lebeau B, Patarin J. Chemical strategies to design textured materials: from microporous and mesoporous oxides to nanonetworks and hierarchical structures. Chem Rev. 2002;102:4093-4138

6. Cheng JY, Ross CA, Smith HI, Thomas EL. Templated self-assembly of block copolymers: top-down helps bottom-up. Adv Mater. 2006;18:2505-2521.

7. Shenhar R, Rotello VM. Nanoparticles: scaffolds and building blocks. Acc Chem Res. 2003;36:549-561.

8. Hamley IW. Nanotechnology with soft materials. Angew Chem Int Ed Engl. 2003;42:1692-1712.

9. Shimizu T. Bottom-up synthesis and morphological control of highaxial-ratio nanostructures through molecular self-assembly. Polym J. 2003;35:1-22.

10. Claridge SA, Castleman AW, Khanna SN, Murray C, Sen A, Weiss PS. Cluster-assembled materials. ACS Nano. 2009;3:244-255.

11. Imai H. Biomineralization I: crystallization and self-organization process. Top Curr Chem. 2007;270:43.

12. Lopes WA, Jaeger HM. Hierarchical self-assembly of metal nanostructures on diblock copolymer scaffolds. Nature. 2001;414:735-738.

13. Ma YR, Qi LM, Ma JM, Cheng HM. Hierarchical, star-shaped $\mathrm{PbS}$ crystals formed by a simple solution route. Cryst Growth Des. 2004;4:351-354.

14. Chen XY, Wang X, Wang ZH, Yang XG, Qian YT. Hierarchical growth and shape evolution of $\mathrm{HgS}$ dendrites. Cryst Growth Des. 2005;5:347-350.

15. Zhang DF, Sun LD, Jia CJ, Yan ZG, You LP, Yan CH. Hierarchical assembly of $\mathrm{SnO}_{2}$ nanorod arrays on alpha- $\mathrm{Fe}_{2} \mathrm{O}_{3}$ nanotubes: a case of interfacial lattice compatibility. J Am Chem Soc. 2005;127:13492-13493.

16. Hu XL, Yu JC, Gong JM. Fast production of self-assembled hierarchical alpha- $\mathrm{Fe}_{2} \mathrm{O}_{3}$ nanoarchitectures. J Phys Chem C. 2007;111: 11180-11185.
17. Liu B, Zeng HC. Room temperature solution synthesis of monodispersed single-crystalline $\mathrm{ZnO}$ nanorods and derived hierarchical nanostructures. Langmuir. 2004;20:4196-4204.

18. Li L, Li Y, Gao SY, Koshizaki N. Ordered $\mathrm{Co}_{3} \mathrm{O}_{4}$ hierarchical nanorod arrays: tunable superhydrophilicity without UV irradiation and transition to superhydrophobicity. J Mater Chem. 2009;19:8366-8371.

19. Yang LX, Zhu YJ, Tong H, Liang ZH, Wang WW. Hierarchical beta$\mathrm{Ni}(\mathrm{OH})_{2}$ and $\mathrm{NiO}$ carnations assembled from nanosheet building blocks. Cryst Growth Des. 2007;7:2716-2719.

20. Liang XH, Xiang JH, Zhang FS, Xing L, Song B, Chen SW. Fabrication of hierarchical $\mathrm{CaCO}_{3}$ mesoporous spheres: particle-mediated selforganization induced by biphase interfaces and SAMs. Langmuir. 2010;26:5882-5888.

21. Wu J, Zhu YJ, Cao SW, Chen F. Hierachically nanostructured mesoporous spheres of calcium silicate hydrate: surfactant-free sonochemical synthesis and drug-delivery system with ultrahigh drugloading capacity. Adv Mater. 2010;22:749-753.

22. Tampieri A, Sprio S, Ruffini A, Celotti G, Lesci IG, Roveri N. From wood to bone: multi-step process to convert wood hierarchical structures into biomimetic hydroxyapatite scaffolds for bone tissue engineering. J Mater Chem. 2009;19:4973-4980.

23. Zhang CM, Yang J, Quan ZW, et al. Hydroxyapatite nano- and microcrystals with multiform morphologies: controllable synthesis and luminescence properties. Cryst Growth Des. 2009;9:2725-2733.

24. Hou ZY, Yang PP, Lian HZ, et al. Multifunctional hydroxyapatite nanofibers and microbelts as drug carriers. Chem Eur J. 2009;15: 6973-6982.

25. Ma MY, Zhu YJ, Li L, Cao SW. Nanostructured porous hollow ellipsoidal capsules of hydroxyapatite and calcium silicate: preparation and application in drug delivery. J Mater Chem. 2008;18:2722-2727.

26. White AA, Best SM, Kinloch IA. Hydroxyapatite-carbon nanotube composites for biomedical applications: a review. Int J Appl Ceramic Technol. 2007;4:1-13.

27. Cai YR, Tang RK. Calcium phosphate nanoparticles in biomineralization and biomaterials. J Mater Chem. 2008;18:3775-3787.

28. Du C, Wang YJ. Progress in the biomineralization study of bone and enamel and biomimetic synthesis of calcium phosphate. J Inorg Mater. 2009;24:882-888.

29. Palmer LC, Newcomb CJ, Kaltz SR, Spoerke ED, Stupp SI. Biomimetic systems for hydroxyapatite mineralization inspired by bone and enamel. Chem Rev. 2008;108:4754-4783.

30. Xiao JW, Zhu YC, Ruan QC, et al. Biomacromolecule and surfactant complex matrix for oriented stack of 2-dimensional carbonated hydroxyapatite nanosheets as alignment in calcified tissues. Cryst Growth Des. 2010;10:1492-1499.

31. Cheng XK, Huang ZL, Li JQ, et al. Self-Assembled growth and pore size control of the bubble-template porous carbonated hydroxyapatite microsphere. Cryst Growth Des. 2010;10:1180-1188.

32. Cheng XK, He QJ, Li JQ, Huang ZL, Chi RA. Control of pore size of the bubble-template porous carbonated hydroxyapatite microsphere by adjustable pressure. Cryst Growth Des. 2009;9:2770-2775.

33. Zhang CM, Cheng ZY, Yang PP, et al. Architectures of strontium hydroxyapatite microspheres: solvothermal synthesis and luminescence properties. Langmuir. 2009;25:13591-13598.

34. Tan SH, Chen XG, Ye Y, Sun J, Dai LQ, Ding Q. Hydrothermal removal of $\mathrm{Sr}^{2+}$ in aqueous solution via formation of $\mathrm{Sr}$-substituted hydroxyapatite. J Hazard Mater. 2010;179:559-563.

35. Hui JF, Xiang GL, Xu XX, Zhuang J, Wang X. Monodisperse F-substituted hydroxyapatite single-crystal nanotubes with amphiphilic surface properties. Inorg Chem. 2009;48:5614-5616.

36. Zhang HG, Zhu QS, Wang Y. Morphologically controlled synthesis of hydroxyapatite with partial substitution of fluorine. Chem Mater. 2005; 17:5824-5830.

37. Liu JK, Cao TJ, Lu Y, Luo CX. Facile preparation of assembly hydroxyapatite spheres to produce nanocomposite. Mater Technol. 2009;24: $88-91$. 
38. Zhang Y, Venugopal JR, El-Turki A, Ramakrishna S, Su B, Lim CT. Electrospun biomimetic nanocomposite nanofibers of hydroxyapatite/ chitosan for bone tissue engineering. Biomaterials. 2008;29: 4314-4322.

39. Shum HC, Bandyopadhyay A, Bose S, Weitz DA. Double emulsion droplets as microreactors for synthesis of mesoporous hydroxyapatite. Chem Mater. 2009;21:5548-5555.

40. Bose S, Saha SK. Synthesis and characterization of hydroxyapatite nanopowders by emulsion technique. Chem Mater. 2003;15:4464 4469.

41. Neira IS, Kolen'ko YV, Lebedev OI, et al. An effective morphology control of hydroxyapatite crystals via hydrothermal synthesis. Cryst Growth Des. 2009;9:466-474.

42. Chaudhry AA, Haque S, Kellici S, et al. Instant nano-hydroxyapatite: a continuous and rapid hydrothermal synthesis. Chem Commun 2006;21:2286-2288.

43. Ma MG, Zhu JF. Solvothermal synthesis and characterization of hierarchically nanostructured hydroxyapatite hollow spheres. Eur J Inorg Chem. 2009;5522-5526.

44. Jevtic M, Mitric M, Skapin S, Jancar B, Ignjatovic N, Uskokovic D. Crystal structure of hydroxyapatite nanorods synthesized by sonochemical homogeneous precipitation. Cryst Growth Des. 2008;8:2217-2222.

45. Ethirajan A, Ziener U, Landfester K. Surface-functionalized polymeric nanoparticles as templates for biomimetic mineralization of hydroxyapatite. Chem Mater. 2009;21:2218-2225.

46. Bigi A, Boanini E, Rubini K. Hydroxyapatite gels and nanocrystals prepared through a sol-gel process. J Solid State Chem. 2004;177:3092-3098.

47. Kithva P, Grondahl L, Martin D, Trau M. Biomimetic synthesis and tensile properties of nanostructured high volume fraction hydroxyapatite and chitosan biocomposite films. J Mater Chem. 2010;20:381-389.

48. Zhang YJ, Lu JJ. A mild and efficient biomimetic synthesis of rodlike hydroxyapatite particles with a high aspect ratio using polyvinylpyrrolidone as capping agent. Cryst Growth Des. 2008;8:2101-2107.

49. López-Macipe A, Gómez-Morales J, Rodríguez-Clemente R. Nanosized hydroxyapatite precipitation from homogeneous calcium/citrate/ phosphate solutions using microwave and conventional heating. Adv Mater. 1998;10:49-53.

50. Gajjeraman S, Narayanan K, Hao JJ, Qin CL, George A. Matrix macromolecules in hard tissues control the nucleation and hierarchical assembly of hydroxyapatite. J Biol Chem. 2007;282:1193-1204.

51. Wang X, Zhuang J, Peng Q, Li YD. Liquid-solid-solution synthesis of biomedical hydroxyapatite nanorods. Adv Mater. 2006;18:2031-2034.

52. Ortega I, Jobbágy M, Ferrer ML, del Monte F. Urease functionalized silica: a biohybrid substrate to drive self-mineralization. Chem Mater. 2008;20:7368-7370.

53. Wang YS, Hassan MS, Gunawan P, Lau R, Wang X, Xu R. Polyelectrolyte mediated formation of hydroxyapatite microspheres of controlled size and hierarchical structure. J Colloid Interface Sci. 2009;339:69-77.
54. Ryu J, Ku SH, Lee H, Park CB. Mussel-inspired polydopamine coating as a universal route to hydroxyapatite crystallization. Adv Funct Mater. 2010;20:2132-2139.

55. Nassif N, Martineau F, Syzgantseva O, et al. In vivo inspired conditions to synthesize biomimetic hydroxyapatite. Chem Mater. 2010;22:3653-3663.

56. Meyers MA, Chen PY, Lin AYM, Seki Y. Biological materials: structure and mechanical properties. Progr Mater Sci. 2008;53:1-206.

57. Wang WW, Zhu YJ. Synthesis of $\mathrm{PbCrO}_{4}$ and $\mathrm{Pb}_{2} \mathrm{CrO}_{5}$ rods via a microwave-assisted ionic liquid method. Cryst Growth Des. 2005;5:505-507.

58. Cui XJ, Yu SH, Li LL, et al. Selective synthesis and characterization of single-crystal silver molybdate/tungstate nanowires by a hydrothermal process. Chem Eur J. 2004;10:218-223.

59. Li YD, Wang JW, Deng ZX, et al. Bismuth nanotubes: a rational lowtemperature synthetic route. J Am Chem Soc. 2001;123:9904-9905.

60. Panda RN, Hsieh MF, Chung RJ, Chin TS. FTIR, XRD, SEM and solid state NMR investigations of carbonate-containing hydroxyapatite nano-particles synthesized by hydroxide-gel technique. J Phys Chem Solids. 2003;64:193-199.

61. Jokanović V, Izvonar D, Dramićanin M, et al. Hydrothermal synthesis and nanostructure of carbonated calcium hydroxyapatite. J Mater Sci Mater Med. 2006;17:539-546.

62. Kumar R, Prakash KH, Cheang P, Khor KA. Temperature driven morphological changes of chemically precipitated hydroxyapatite nanoparticles. Langmuir. 2004;20:5196-5200.

63. Kuriakose TA, Kalkura SN, Palanichamy M, et al. Synthesis of stoichiometric nano crystalline hydroxyapatite by ethanol-based sol-gel technique at low temperature. J Cryst Growth. 2004;263:517-523.

64. Ma MG, Zhu YJ, Chang J. Monetite formed in mixed solvents of water and ethylene glycol and its transformation to hydroxyapatite. $J$ Phys Chem B. 2006;110:14226-14230.

65. Shlyakhova EV, Yudanov NF, Shubin YV, Yudanova LI, Bulusheva LG, Okotrub AV. Catalytic synthesis of carbon nanotubes using Ni- and Co-doped calcium tartrates. Carbon. 2009;47:1701-1707.

66. Chow LC. Development of self-setting calcium phosphate cements. J Ceramic Soc Japan. 1991;99:954-964.

67. Xu YY, Chen DR, Jiao XL. Fabrication of CuO pricky microspheres with tunable size by a simple solution route. J Phys Chem B. 2005;109: $13561-13566$

68. Lu CH, Qi LM, Yang JH, et al. One-pot synthesis of octahedral $\mathrm{Cu}_{2} \mathrm{O}$ nanocages via a catalytic solution route. Adv Mater. 2005;17: 2562-2567.

69. Koutsopoulos S. Kinetic study on the crystal growth of hydroxyapatite Langmuir. 2001;17:8092-8097.

70. Wang X, Zhuang J, Peng Q, Li YD. Liquid-solid-solution synthesis of biomedical hydroxyapatite nanorods. Adv Mater. 2006;18: 2031-2034.

71. Wang JW, Shaw LL. Morphology-enhanced low-temperature sintering of nanocrystalline hydroxyapatite. Adv Mater. 2007;19:2364-2369.
International Journal of Nanomedicine

\section{Publish your work in this journal}

The International Journal of Nanomedicine is an international, peerreviewed journal focusing on the application of nanotechnology in diagnostics, therapeutics, and drug delivery systems throughout the biomedical field. This journal is indexed on PubMed Central,

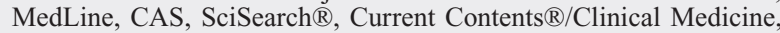

\section{Dovepress}

Journal Citation Reports/Science Edition, EMBase, Scopus and the Elsevier Bibliographic databases. The manuscript management system is completely online and includes a very quick and fair peer-review system, which is all easy to use. Visit http://www.dovepress.com/ testimonials.php to read real quotes from published authors. 